\title{
The Potential Protective Effect of Physalis peruviana L. against Carbon Tetrachloride-Induced Hepatotoxicity in Rats Is Mediated by Suppression of Oxidative Stress and Downregulation of MMP-9 Expression
}

\author{
Ebtisam M. Al-Olayan, ${ }^{1}$ Manal F. El-Khadragy, ${ }^{1,2}$ Ahmed M. Aref, ${ }^{3}$ Mohamed S. Othman, \\ Rami B. Kassab, ${ }^{2,5}$ and Ahmed E. Abdel Moneim ${ }^{2,6}$ \\ ${ }^{1}$ Zoology Department, Faculty of Science, King Saud University, Riyadh 11451, Saudi Arabia \\ ${ }^{2}$ Zoology and Entomology Department, Faculty of Science, Helwan University, Cairo 11795, Egypt \\ ${ }^{3}$ Biological Science Department, Faculty of Dentistry, Modern Sciences and Arts (MSA) University, Giza 12111, Egypt \\ ${ }^{4}$ Biochemistry and Molecular Biology Department, Faculty of Biotechnology, Modern Sciences and Arts (MSA) University, \\ Giza 12111, Egypt \\ ${ }^{5}$ Experimental Biology Department, Faculty of Science, Masaryk University, 62500 Brno, Czech Republic \\ ${ }^{6}$ Biochemistry and Molecular Biology Department, Asturias Institute of Biotechnology, University of Oviedo, 33006 Oviedo, Spain
}

Correspondence should be addressed to Ahmed E. Abdel Moneim; abdelahmed.uo@uniovi.es

Received 29 November 2013; Revised 3 February 2014; Accepted 6 February 2014; Published 27 April 2014

Academic Editor: Vladimir Jakovljevic

Copyright (C) 2014 Ebtisam M. Al-Olayan et al. This is an open access article distributed under the Creative Commons Attribution License, which permits unrestricted use, distribution, and reproduction in any medium, provided the original work is properly cited.

\begin{abstract}
The active constituent profile in Cape gooseberry (Physalis peruviana L.) juice was determined by GC-MS. Quercetin and kaempferol were active components in the juice. In this study we have evaluated its potential protective effect on hepatic injury and fibrosis induced by carbon tetrachloride $\left(\mathrm{CCl}_{4}\right)$. Twenty-eight rats divided into 4 groups: Group I served as control group, and Group II received weekly i.p. injection of $2 \mathrm{~mL} \mathrm{CCl}_{4} / \mathrm{kg}$ bwt for 12 weeks. Group III were supplemented with Physalis juice via the drinking water. The animals of Group IV received Physalis juice as Group III and also were intraperitoneally injected weekly with $2 \mathrm{~mL} \mathrm{CCl}_{4} / \mathrm{kg}$ bwt for 12 weeks. Hepatoprotective effect was evaluated by improvement in liver enzymes serum levels, reduction in collagen areas, downregulation in expression of the fibrotic marker MMP-9, reduction in the peroxidative marker malonaldehyde and the inflammatory marker nitric oxide, and restoration of the activity of antioxidant enzymatic and nonenzymatic systems, namely, glutathione content, superoxide dismutase, catalase, glutathione-S-transferase, glutathione peroxidase, and glutathione reductase activities. The results show that the potential hepatoprotective effects of Physalis peruviana may be due to physalis acts by promotion of processes that restore hepatolobular architecture and through the inhibition of oxidative stress pathway.
\end{abstract}

\section{Introduction}

Liver diseases are amongst the most serious health problems in the world today and their prevention and treatment options still remain limited despite tremendous advances in modern medicine. The pathogenesis of hepatic diseases as well as the role of oxidative stress and inflammation therein is well established and, accordingly, blocking or retarding the chain reactions of oxidation and inflammation process could be promising therapeutic strategies for prevention and treatment of liver injury [1].

Vitaglione et al. [2] suggested that reactive oxygen species (ROS) including superoxide and hydroxyl radicals are known to play an important role in liver disease's pathology and progression and have been proven to associate with the intoxication by $\mathrm{CCl}_{4}$. Documented evidences suggested that $\mathrm{CCl}_{4}$ has been commonly used as hepatotoxins in experimental hepatopathy [3]. The first metabolite of $\mathrm{CCl}_{4}$ trichloromethyl 
free radical is believed to initiate the biochemical processes leading to oxidative stress, which is the direct cause of many pathological conditions such as diabetes mellitus, cancer, hypertension, kidney and liver damages, and even death $[4$, $5]$.

In recent years, considerably clinical and experimental evidences show that oxidative stress caused by an imbalance between the oxidant and antioxidant systems of the body in favor of the oxidants should be a major apoptotic stimulus in the different types of acute and chronic liver injury and hepatic fibrosis [6].

Hepatic fibrosis induced by $\mathrm{CCl}_{4}$ is associated with the exacerbation of lipid peroxidation and the depletion of antioxidant status [7]. Accordingly, successful antioxidant interventions, which to date has attracted intensive interests from investigators, offer insights into delaying or preventing occurrence and development of hepatic fibrosis and may be a potential and effective therapeutic strategy for prevention and treatment of hepatic fibrosis [8].

There are a number of evidences indicating that natural substances from edible and medicinal plants exhibited strong antioxidant activity that could act against hepatic toxicity caused by various toxicants $[9,10]$. One of those candidate plants is Cape gooseberry (Physalis peruviana L.). Various bioactive compounds (withanolides and phenolics) are reported to be present in physalis [11]. Some of these compounds have a strong antioxidant property and prevent peroxidative damage to liver microsomes and hepatocytes [12].

We aimed in this study to evaluate the potential hepatoprotective effect of Physalis peruviana against $\mathrm{CCl}_{4}$-induced hepatotoxicity and liver fibrosis in rats.

\section{Materials and Methods}

2.1. Chemicals. Carbon tetrachloride $\left(\mathrm{CCl}_{4}\right)$ and Tris- $\mathrm{HCl}$ buffer were purchased from Sigma (St. Louis, MO, USA). Perchloric acid, thiobarbituric acid (TBA), and trichloroacetic acid (TCA) were purchased from Merck. All other chemicals and reagents used in this study were of analytical grade. Double-distilled water was used as the solvent.

2.2. Animals. Adult male Wistar albino rats weighing 200$250 \mathrm{~g}$ (8-10 weeks) were obtained from the Holding Company for Biological Products and Vaccines (VACSERA, Cairo, Egypt). The animals were kept in wire bottomed cages in a room under standard condition of illumination with a 12 hour light-dark cycle $55+5 \%$ relative humidity and at 25 $\pm 2^{\circ} \mathrm{C}$ for one week until the beginning of treatment. They were provided with tap water and balanced diet ad libitum. All animals have received human care in compliance with the state authorities following the Egyptian rules of animal protection.

2.3. Plant Material. Physalis peruviana L. fresh fruits were collected from market of East Cairo, Egypt, in the months of February-March, 2012. The plant material was authenticated in Botany Department, Faculty of Science, Helwan University, Cairo, Egypt, on the basis of taxonomic characters and by direct comparison with the herbarium specimens available at the herbarium of the Botany Department.

2.4. Physalis Juice Preparation and Stability. The fresh fruits of Physalis peruviana L. (10 kg) were separated from their calyxes and homogenized. The pulp was filtered off, the filtrate was clear and yellow in colour, and then the filtrate was immediately diluted with distilled water in ratio $1: 5(\mathrm{~V} / \mathrm{V})$ and stored at $4^{\circ} \mathrm{C}$ for no longer than 2 months. Physalis juice stability was assessed by measuring initial total phenolic and flavonoid contents and evaluating the alterations after 2 and 3 days of exposure to the same conditions as the juice supplied to the animals.

\subsection{Measurement of Flavonoids, Total Polyphenols, and In Vitro Free Radical Scavenging Assays}

2.5.1. Determination of Total Phenols. The total polyphenolic contents (TPC) were measured using Folin-Ciocalteau reagent based on the oxidation of polyphenols to a blue colored complex with an absorbance maximum of $750 \mathrm{~nm}$. Calibration curve was prepared using gallic acid as standard for TPC which was measured as mg gallic acid equivalents (GAE) per milliliter of the sample $(\mu \mathrm{g} / \mathrm{mL})$.

2.5.2. Determination of Flavonoid Content. For the assessment of flavonoids a colorimetric method was used. Briefly, $1.50 \mathrm{~mL}$ of the deionized water was added to $0.25 \mathrm{~mL}$ of the sample and then $90 \mathrm{uL}$ of $5 \%$ sodium nitrite $\left(\mathrm{NaNO}_{2}\right)$ was added. Six min later, after addition of $180 \mathrm{uL}$ of $10 \% \mathrm{AlCl}_{3}$, mixture was allowed to stand for another $5 \mathrm{~min}$ before adding $0.6 \mathrm{~mL}$ of $1 \mathrm{M} \mathrm{NaOH}$. By adding deionized water and mixing well, final volume was made up to $3 \mathrm{~mL}$. The absorbance was measured at a fixed wavelength $510 \mathrm{~nm}$. Calibration curve was prepared using quercetin as standard for total flavonoids which was measured as mg quercetin equivalents $(\mathrm{QE})$ per milliliter of the sample $(\mu \mathrm{g} / \mathrm{mL})$.

2.5.3. Determination of DPPH Radical Scavenging Activity. The free radical scavenging capacity was evaluated by the 2, 2-diphenyl -1-picrylhydrazyl (DPPH) assay. In its radical form, DPPH is monitored at $517 \mathrm{~nm}$ but, upon reduction by an antioxidant or a radical species, the absorption decreases. Briefly, $1 \mathrm{~mL}$ of $0.25 \mathrm{mM}$ solution of DPPH in methanol was added to $50,100,150$, and $200 \mathrm{uL}$ of sample in 950 , 900,850 , and $800 \mu \mathrm{L}$ methanol, respectively. After $20 \mathrm{~min}$, the absorbance was measured. Ascorbic acid was used as a positive control. The percentage DPPH decolorisation of the sample was calculated by the equation, $\% \mathrm{DPPH}$ scavenging = $\left[\left(A_{\text {control }}-A_{\text {sample }}\right) / A_{\text {control }}\right]-100$, where $A$ is the absorbance.

2.5.4. Determination of Superoxide Anion Scavenging Activity. The superoxide anion scavenging activity was determined by the method of Nishikimi et al. [13]. Superoxide anion derived from dissolved oxygen by a phenazine methosulfate 
(PMS)/NADH coupling reaction reduces nitroblue tetrazolium (NBT), which forms a violet colored complex. A decrease in color after addition of the antioxidant is a measure of its superoxide scavenging activity. To the reaction mixture containing phosphate buffer (100 mM, pH 7.4), NBT (1 mM) solution, NADH $(1 \mathrm{mM}), 50,100,150$, and $200 \mathrm{uL}$ of sample in $950,900,850$, and $800 \mu \mathrm{L}$ methanol, respectively, and $1 \mathrm{~mL}$ of $1 \mathrm{mM}$ PMS were added. After incubation at $25^{\circ} \mathrm{C}$ for $5 \mathrm{~min}$, the absorbance was measured at $560 \mathrm{~nm}$ against a blank. Vit. $\mathrm{C}$ was used as a positive control.

\subsubsection{Determination of Nitric Oxide Radical Inhibition Activ-} ity. The nitric oxide radical inhibition activity was measured using Griess reagent. Briefly, sodium nitroprusside $(10 \mathrm{mM})$ in phosphate buffered saline was mixed with 50 , 100,150 , and $200 \mathrm{uL}$ of sample in 950, 900, 850, and $800 \mu \mathrm{L}$ methanol, respectively, and incubated at room temperature for $150 \mathrm{~min}$ followed by addition of $0.5 \mathrm{~mL}$ of Griess reagent ( $1 \%$ sulfanilamide, $2 \% \mathrm{H}_{3} \mathrm{PO}_{4}$, and $0.1 \% \mathrm{~N}$-(1naphthyl)ethylenediamine dihydrochloride). The absorbance of the chromophore formed was read at $546 \mathrm{~nm}$.

\subsubsection{Determination of Total Antioxidant Potential Activity.} The total antioxidant potential was measured by the ability of sample to scavenge thiobarbituric acid reactive substances (TBARS) [14]. Briefly, 50, 100, 150, and $200 \mathrm{uL}$ of the different samples were added to the $10 \%$ liver homogenate. Lipid peroxidation was initiated by addition of $100 \mu \mathrm{L}$ of $15 \mathrm{mM} \mathrm{FeSO}_{4}$ solution to $3 \mathrm{~mL}$ of liver homogenate (final concentration was $0.5 \mathrm{mM}$ ). After $30 \mathrm{~min}, 100 \mu \mathrm{L}$ of this reaction mixture was taken in a tube containing $1.5 \mathrm{~mL}$ of $0.67 \%$ thiobarbituric acid (TBA) in 50\% acetic acid. Samples were incubated at $37^{\circ} \mathrm{C}$ for $1 \mathrm{hr}$, and then lipid peroxidation was measured using the reaction with TBA. The absorbance of the organic layer was measured at $532 \mathrm{~nm}$. All reactions were carried out in triplicate. Vitamin C (Vit. C) was used as the positive control. The percentage of inhibition of lipid peroxidation was calculated, by the formula Inhibition $(\%)=\left(A_{\text {control }}-\right.$ $\left.A_{\text {sample }}\right) \times 100 / A_{\text {control }}$.

2.6. Gas Chromatography-Mass Spectrometry (GC-MS) Analysis. The GC-MS analysis of physalis juice was performed with Thermo Scientific, Trace GC Ultra \& ISQ Single Quadruple MS. The inert gas helium (99.9995\%) was used as carrier gas, at flow rate of $1.5 \mathrm{~mL} / \mathrm{min}$; split ratio $10: 1$; sample size, $1 \mu \mathrm{L}$ injected using the splitless injection technique; fused capillary silica column TG-5MS $(30 \mathrm{~m} \times 0.25 \mathrm{~mm} \times$ $0.25 \mu \mathrm{m})$. Temperatures: injector: $260^{\circ} \mathrm{C}$, detector: $300^{\circ} \mathrm{C}$, column: $70^{\circ} \mathrm{C}, 10^{\circ} \mathrm{C} \mathrm{min}{ }^{-1}$, and $260^{\circ} \mathrm{C}(10 \mathrm{~min})$. The total GC running time is at $60 \mathrm{~min}$. The MS was taken at $70 \mathrm{eV}$. The MS scan parameters included a mass range of $\mathrm{m} / \mathrm{z} 40-1000$, a scan interval of $0.5 \mathrm{~s}$, a scan speed of $2000 \mathrm{amu} \mathrm{s}^{-1}$, and a detector voltage of $1.0 \mathrm{kV}$. Identification of compounds was conducted using the database of Wiley9 combined with NIST 11 mass spectral database. The name, molecular weight, molecular formula, and area under peak of the components of the test materials were ascertained.
2.7. Experimental Protocol. To study the protective effects of physalis juice on carbon tetrachloride mediated liver toxicity, twenty eight adult male rats were randomly allocated to four groups, seven rats of each. Group I (Con) served as control and received $300 \mu \mathrm{L}$ of saline by intraperitoneal (i.p.) injection route each week. Group II $\left(\mathrm{CCl}_{4}\right)$ received weekly i.p. injection of $2 \mathrm{~mL} \mathrm{CCl}_{4} / \mathrm{kg}$ bwt for 12 weeks as described by Sohn et al. [15]. Group III (physalis) received juice supplied on dark water bottles and renewed every 2-3 days. The animals of Group IV (physalis $+\mathrm{CCl}_{4}$ ) received physalis juice as Group III and were also intraperitoneally injected weekly with $2 \mathrm{~mL} \mathrm{CCl} / \mathrm{kg}$ bwt for 12 weeks. After one week of the last i.p. injection of $\mathrm{CCl}_{4}$, the animals of all groups were anesthetized with chloroform and blood sampling was performed by cardiac puncture. The collected blood samples were allowed to clot for half an hour at $8^{\circ} \mathrm{C}$. Serum was separated by centrifugation at $3000 \mathrm{rpm}$ for $15 \mathrm{~min}$ at $4^{\circ} \mathrm{C}$ to separate serum, stored at $-20^{\circ} \mathrm{C}$, and used for the estimation of marker enzymes, namely, alanine aminotransferase (ALT), aspartate aminotransferase (AST), $\gamma$-glutamyl transpeptidase $(\gamma \mathrm{GT})$, alkaline phosphatase (ALP), and total bilirubin (TB). The livers were dissected out immediately, washed, and homogenized immediately to give $50 \%(\mathrm{w} / \mathrm{v})$ homogenate in ice-cold medium containing $50 \mathrm{mM}$ Tris- $\mathrm{HCl}, \mathrm{pH}$, 7.4. The homogenate was centrifuged at $3000 \mathrm{rpm}$ for $10 \mathrm{~min}$ at $4^{\circ} \mathrm{C}$. The supernatant (10\%) was used for the various biochemical determinations.

2.8. Histopathological Examination. Tissue samples were fixed in $10 \%$ neutral formalin for $24 \mathrm{~h}$ and paraffin blocks were obtained and routinely processed for light microscopy. Slices of 4-5 $\mu \mathrm{m}$ were obtained from the prepared blocks and stained with hematoxylin and eosin as well as Sirius Red for hepatic fibrosis. The preparations obtained were visualized using a Nikon microscopy at a magnification of 400x.

2.9. Liver Function Tests. Colorimetric determination of alanine aminotransferase or aspartate aminotransferase, ALT or AST, was estimated by measuring the amount of pyruvate or oxaloacetate produced by forming 2, 4dinitrophenylhydrazine according to the method of Reitman and Frankel [16]. Glutamyl transferase and alkaline phosphatase, $\gamma$ GT and ALP, were assayed using kits provided by Randox Laboratories Co. according to the methods described by Szasz [17] and Belfield and Goldberg [18], respectively. Also, total bilirubin, TB, in serum was assayed according to the method of Garber [19].

2.10. Oxidative Stress Markers. Serum and homogenates of liver were used to determine malondialdehyde (MDA) as indicator of lipid peroxidation by reaction of thiobarbituric acid according to the method of Ohkawa et al. [20], nitrite/nitrate (nitric oxide, NO) was measured using the method of Green et al. [21] and glutathione (GSH) was measured as described by Ellman [22].

2.11. Enzymatic Antioxidant Status. Homogenates of liver were used for determination of superoxide dismutase (SOD) 


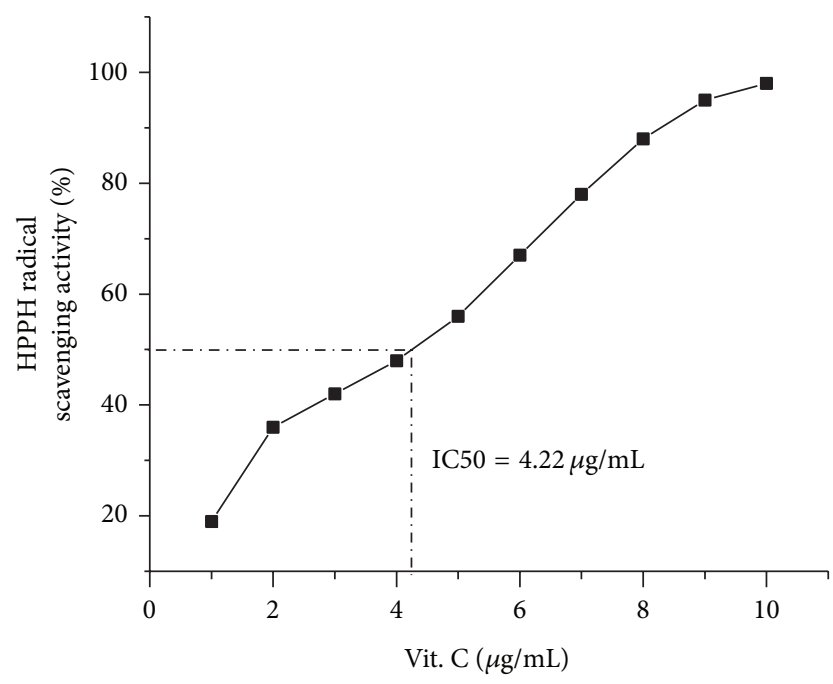

(a)

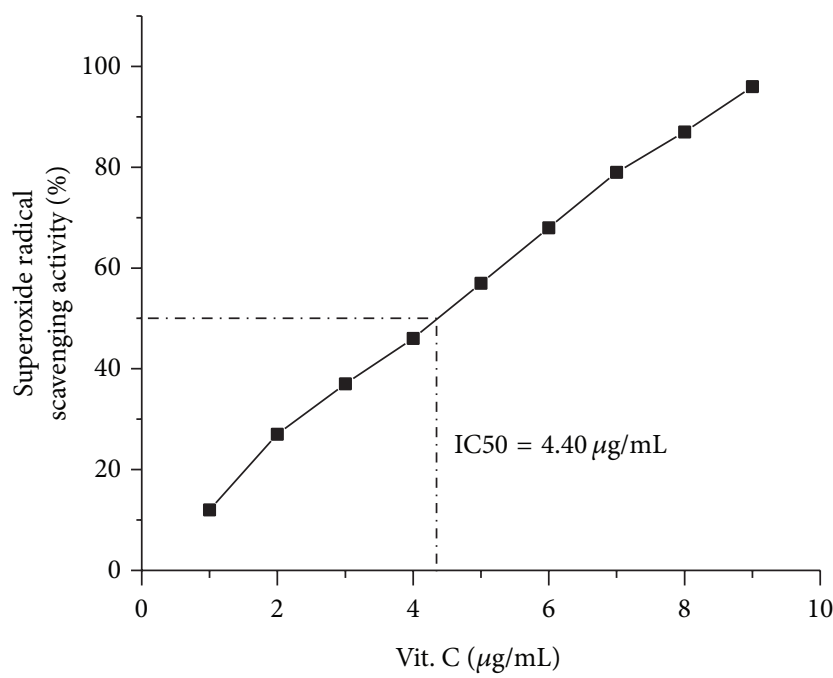

(c)

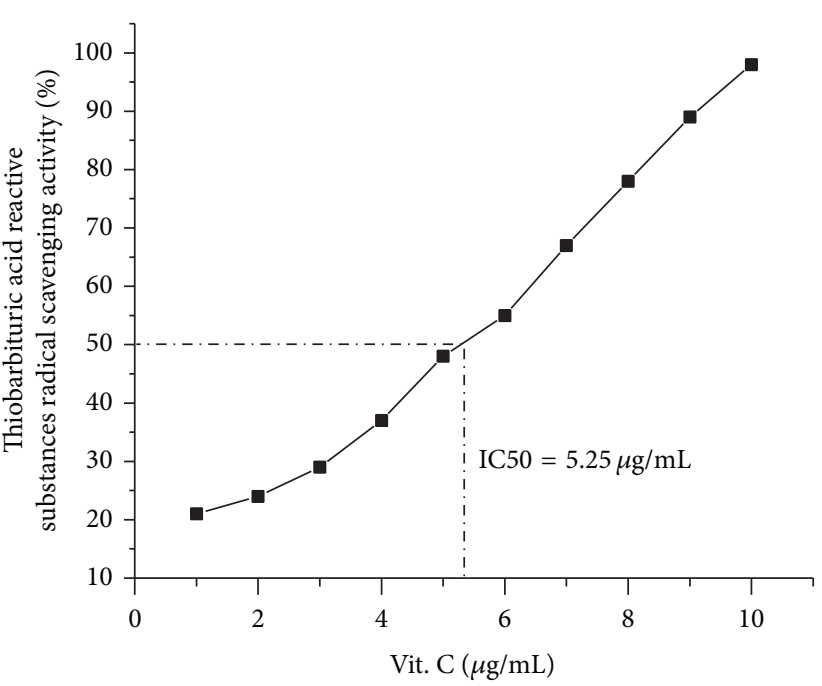

(e)

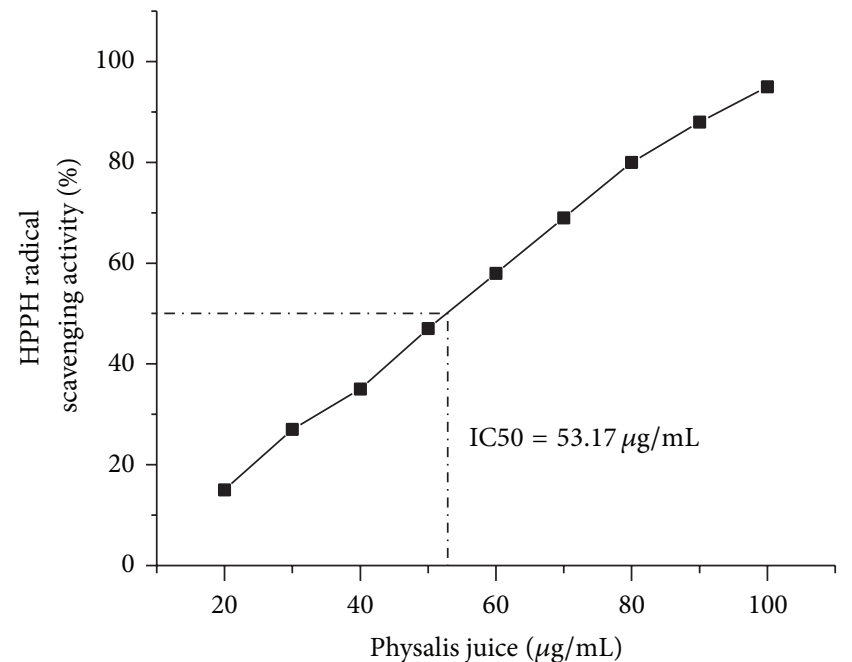

(b)

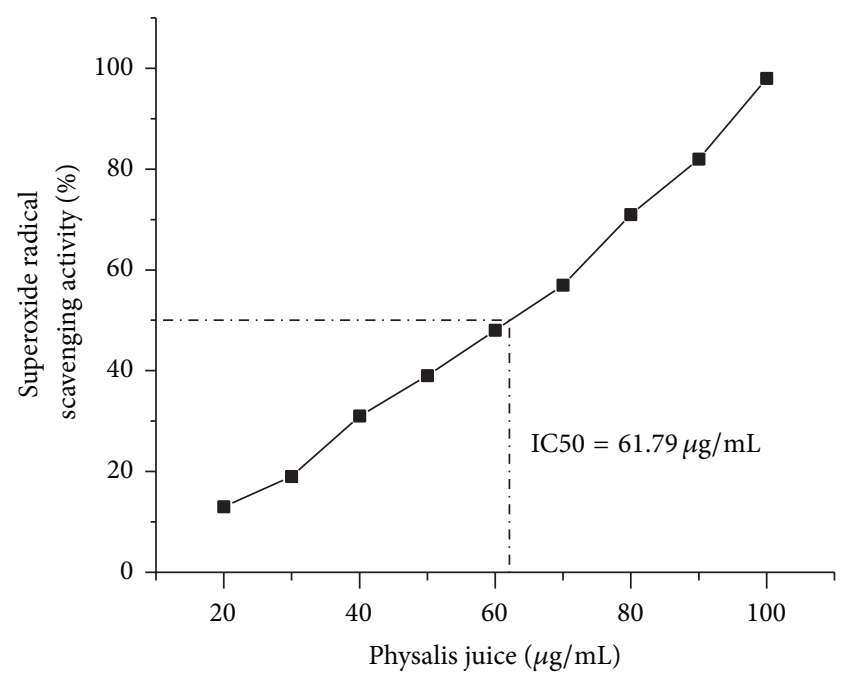

(d)

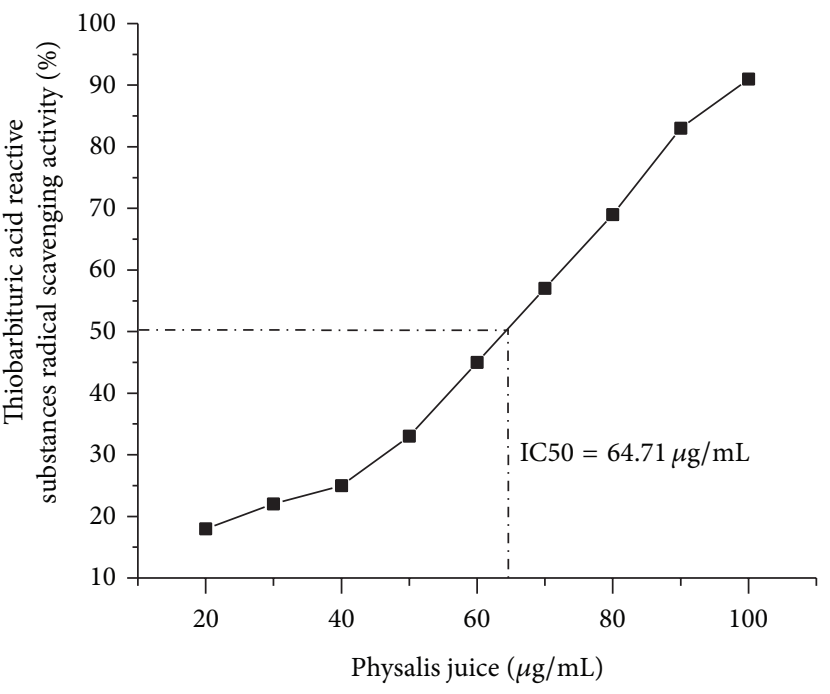

(f)

FIgure 1: Continued. 


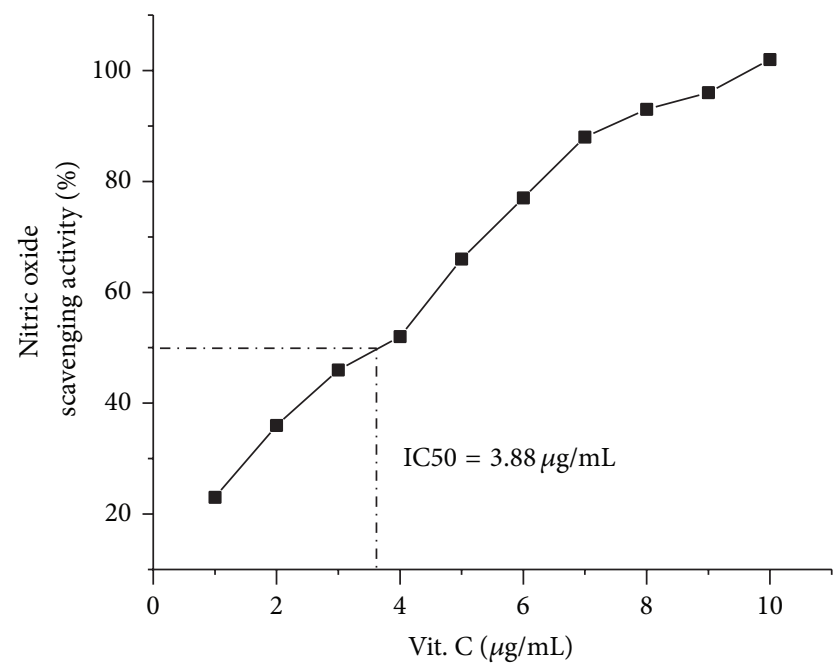

(g)

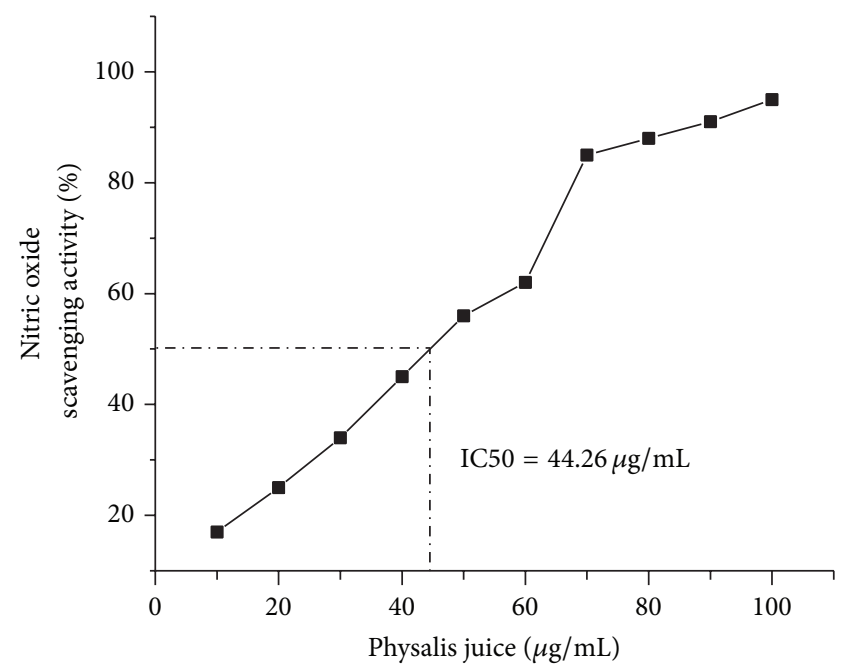

(h)

FIGURE 1: DPPH, superoxide, thiobarbituric acid reactive substances, and nitric oxide radicals scavenging activities of physalis juice and Vit. C. IC 50 values denote the concentration of sample which is required to scavenge $50 \%$ of the respective free radicals. Data are represented as mean \pm SEM of two independent experiments each performed in triplicate as published in Abdel Moneim and El-Dieb [27].

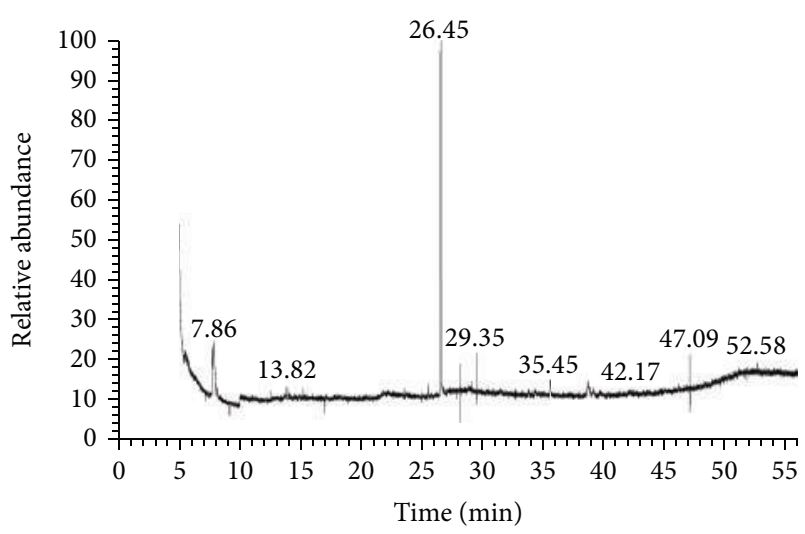

FIGURE 2: GC-MS chromatogram of physalis juice.

as described by Nishikimi et al. [13], catalase (CAT) as described by Aebi [23], glutathione peroxidase (GPx) as described by Paglia and Valentine [24], glutathione-Stransferase (GST) as described by Habig et al. [25], and glutathione reductase (GRd) as described by Factor et al. [26] .

2.12. Real Time PCR. Total RNA was isolated from the liver tissue using an RNeasy Plus Minikit (Qiagen, Valencia, CA). One microgram total RNA and random primers were used for cDNA synthesis using the RevertAid H Minus Reverse Transcriptase (Fermentas, Thermo Fisher Scientific Inc., Canada). For real time PCR analysis, the cDNA samples are run in triplicate and $\beta$-actin is used as reference gene. Each PCR amplification includes nontemplate controls containing all reagents except cDNA. Real time PCR reactions were performed using Power SYBR Green (Life Technologies, CA) and was conducted on the Applied Biosystems 7500 Instrument. The typical thermal profile is $95^{\circ} \mathrm{C}$ for $3 \mathrm{~min}$, followed by 40 cycles of $95^{\circ} \mathrm{C}$ for $15 \mathrm{~s}$ and $56^{\circ} \mathrm{C}$ for $30 \mathrm{~s}$. After PCR amplification, the $\Delta \mathrm{Ct}$ is calculated by subtraction of the $\beta$-actin Ct from each sample Ct. The method of Pfaffl was used for data analysis. The PCR primers for INOS, GPx, and GRd genes were synthesized by Jena Bioscience GmbH (Jena, Germany). Primers were designed using Primer-Blast program from NCBI. For a reference gene, the $\beta$-actin is used. The primer sets used the following.

$$
\begin{aligned}
& \text { iNOS (S): } 5^{\prime} \text {-GAAAGAACTCGGGCATACCT-3' } \\
& \text { iNOS (AS): } 5^{\prime} \text {-GGCGAAGAACAATCCACAAC-3' } \\
& \text { GPx (S): } 5^{\prime} \text {-CGGTTTCCCGTGCAATCAGT-3 }{ }^{\prime} . \\
& \text { GPx (AS): } 5^{\prime} \text {-ACACCGGGGACCAAATGATG-3' } \\
& \text { GRd (S): } 5^{\prime} \text {-AGCCCACAGCGGAAGTCAAC-3' } \\
& \text { GRd (AS): } 5^{\prime} \text {-CAATGTAACCGGCACCCACA-3' } \\
& \beta \text {-Actin (S): } 5^{\prime} \text {-GGCATCCTGACCCTGAAGTA-3' } \\
& \beta \text {-Actin (AS): } 5^{\prime} \text {-GGGGTGTTGAAGGTCTCAAA- } \\
& 3^{\prime} \text {. }
\end{aligned}
$$

2.13. Immunohistochemistry for Detection of MMP-9. For immunohistochemistry, liver sections $(4 \mu \mathrm{m})$ were deparaffinized and then boiled to unmask antigen sites; the endogenous activity of peroxidase was quenched with $0.03 \% \mathrm{H}_{2} \mathrm{O}_{2}$ in absolute methanol. Liver sections were incubated overnight at $4^{\circ} \mathrm{C}$ with a 1:200 dilution of goat polyclonal MMP-9 antibodies (Santa Cruz CA, USA) in phosphate buffered saline (PBS). After removal of the unbound primary antibodies by rinsing with PBS, slides were incubated with a $1: 500$ dilution of biotinylated anti-goat secondary antibody. Bound antibodies were detected with avidin biotinylated peroxidase complex ABC-kit Vectastain and the chromogen 3,3' diaminobenzidine tetrachloride $(\mathrm{DAB})$ is used as substrate. After appropriate washing in PBS, slides were counterstained 

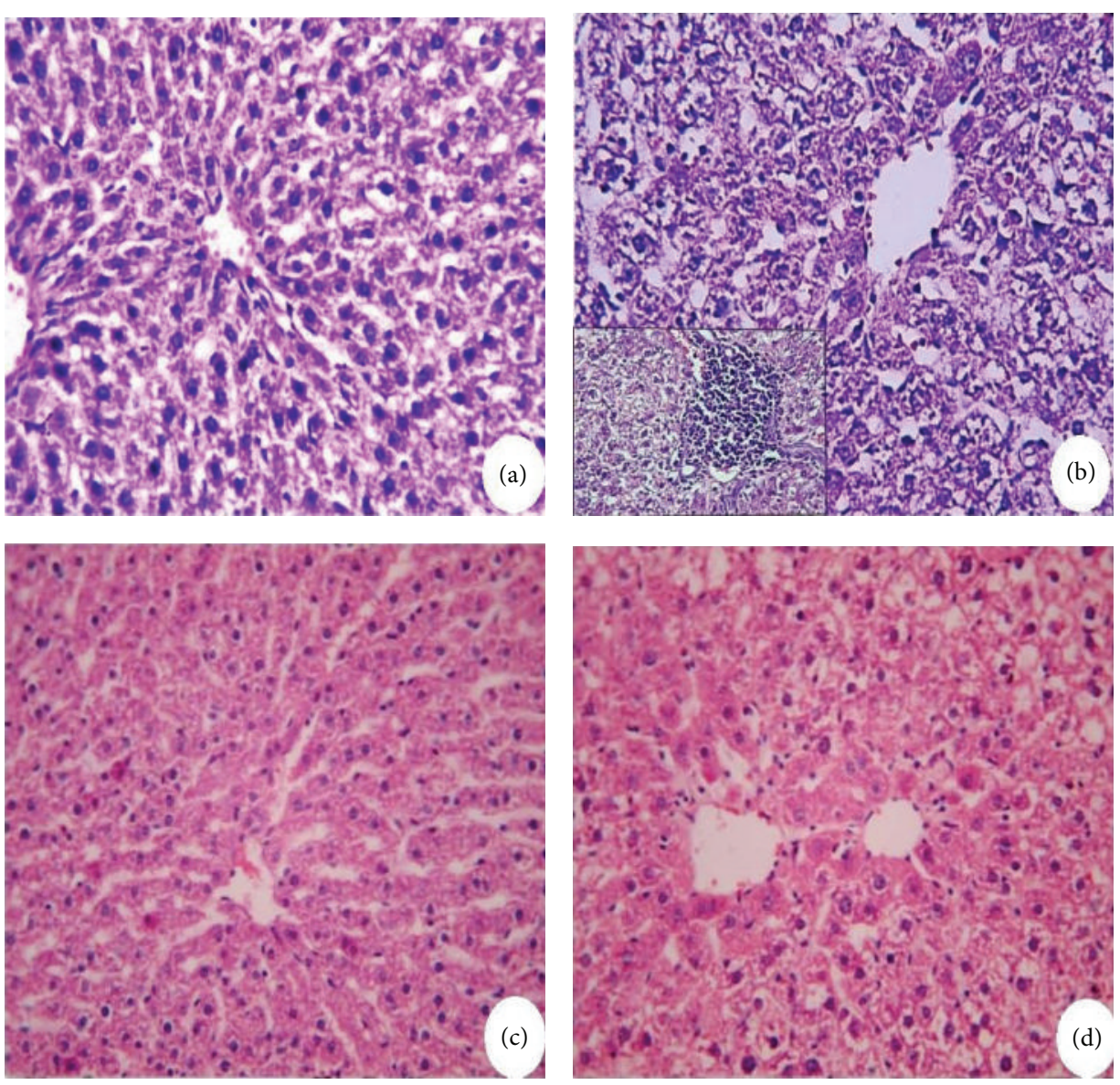

FIGURE 3: Photomicrographs for liver sections stained with hematoxylin and eosin (H\&E). (a) Control rat showing the normal hepatocytes architecture. (b) Rats liver treated with $\mathrm{CCl}_{4}$ showing severe hepatic lesions, degenerated and ballooned/necrotic hepatocytes with lymphocyte cells infiltration (corner). (c) Liver treated with physalis similar to control group. (d) Rat liver treated with physalis $+\mathrm{CCl}_{4}$ showing maintained hepatic architecture, with minimal damage. Original magnification 400x.

with hematoxylin. All sections were incubated under the same conditions with the same concentration of antibodies and at the same time; so the immunostaining was comparable among the different experimental groups.

2.14. Statistical Analysis. Differences between obtained values (mean \pm SEM) were carried out by one-way analysis of variance (ANOVA) followed by the Duncan test. A $P$ value of 0.05 or less was taken as a criterion for a statistically significant difference.

\section{Results}

3.1. Phytochemical Screening and GC-MS Findings. Table 1 shows the flavonoids and total polyphenolic contents of Physalis peruviana L. fruit juice (physalis juice). Flavonoids content in physalis juice was $89.4 \mu \mathrm{g} / \mathrm{mg}$ quercetin equivalents of flavonoids/mL juice. The total polyphenolic content was $121.3 \mu \mathrm{g} / \mathrm{mg}$ gallic acid equivalent of polyphenols $/ \mathrm{mL}$ juice. According to the present results, no significant changes were observed between the initial and final flavonoids and phenolics contents indicating the stability of physalis juice.
TABLE 1: Total flavonoids and polyphenolic contents of physalis juice in different conditions.

\begin{tabular}{lcc}
\hline Conditions & Total phenolics $^{\mathrm{a}}$ & Total flavonoid $^{\mathrm{b}}$ \\
\hline Physalis juice, fresh & $121.3 \pm 4.65$ & $89.4 \pm 4.82$ \\
Physalis juice, store $^{*}$ & $113.5 \pm 5.31$ & $81.7 \pm 3.74$ \\
\hline
\end{tabular}

${ }^{a}$ Flavonoids are expressed as $\mu \mathrm{g} / \mathrm{mg}$ quercetin equivalents of flavonoids $/ \mathrm{mL}$ juice. ${ }^{\mathrm{b}}$ Total polyphenols are expressed as $\mu \mathrm{g} / \mathrm{mg}$ gallic acid equivalent of polyphenols/mL juice. Data are represented as mean \pm SEM of two independent experiments each performed in duplicate. ${ }^{*}$ Stored at room temperature for 3 days.

Figure 1 shows the reduction potential of physalis juice. The order of the reduction potential was physalis juice < Vit. C. Analysis of the free radical scavenging activities of the juice revealed a concentration-dependent antiradical activity resulting from reduction of $\mathrm{DPPH}^{\circ}, \mathrm{O}^{\circ}$, TBARS and nitric oxide radicals to nonradical form [27]. The scavenging activity of Vit. C, a known antioxidant, is used as positive control.

GC-MS chromatogram of the physalis (Figure 2) showed 29 peaks indicating the presence of 29 phytochemical 
TABLE 2: Serum levels of liver enzymes in different studied groups.

\begin{tabular}{lcccc}
\hline Parameters & Group I & Group II & Group III & Group IV \\
\hline GPT $(\mathrm{U} / \mathrm{mL})$ & $70.12 \pm 1.88$ & $153.91 \pm 1.56^{\mathrm{a}}$ & $68.47 \pm 1.23$ & $79.10 \pm 5.12^{\mathrm{b}}$ \\
GOT $(\mathrm{U} / \mathrm{mL})$ & $56.08 \pm 1.30$ & $123.75 \pm 7.21^{\mathrm{a}}$ & $56.33 \pm 1.21$ & $57.08 \pm 1.45^{\mathrm{b}}$ \\
$\gamma$-GT $(\mathrm{U} / \mathrm{L})$ & $38.77 \pm 2.66$ & $52.80 \pm 1.60^{\mathrm{a}}$ & $34.87 \pm 1.21$ & $35.39 \pm 0.56^{\mathrm{b}}$ \\
ALP $(\mathrm{IU} / \mathrm{L})$ & $147.73 \pm 4.07$ & $244.32 \pm 7.52^{\mathrm{a}}$ & $116.48 \pm 5.31^{\mathrm{a}}$ & $165.28 \pm 7.10^{\mathrm{b}}$ \\
TB $(\mathrm{mg} / \mathrm{dL})$ & $2.64 \pm 0.08$ & $4.19 \pm 0.08^{\mathrm{a}}$ & $2.81 \pm 0.05$ & $3.20 \pm 0.09^{\mathrm{ab}}$ \\
\hline
\end{tabular}

Values are means $\pm \operatorname{SEM}(n=7)$.

${ }^{\mathrm{a}} P<0.05$, significant change with respect to Group I; ${ }^{\mathrm{b}} P<0.05$, significant change with respect to Group II.
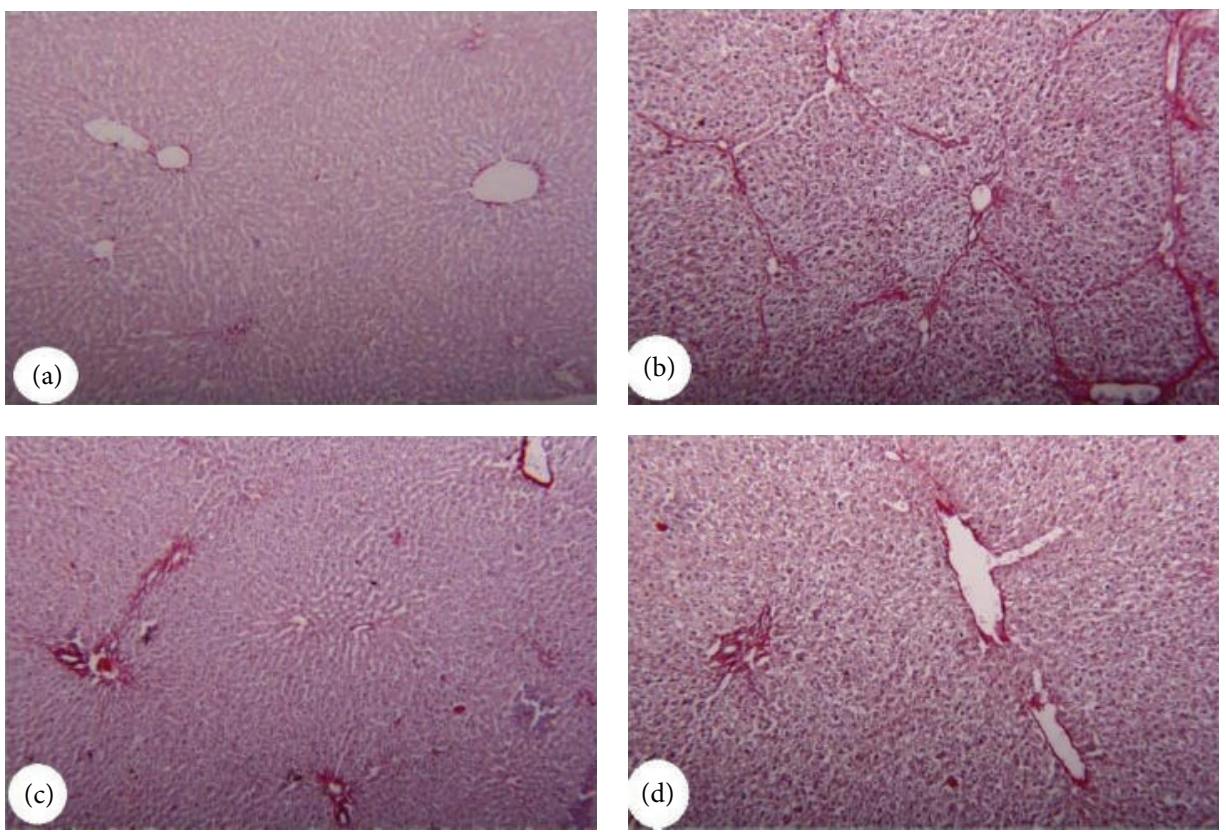

FIGURE 4: Photomicrographs of liver tissue stained with Sirius Red showing. (a) Control group showing absence of collagen fibers. (b) $\mathrm{CCl}_{4}$ group had developed extensive fibrosis in the periportal area and more fibrillar collagen deposition. (c) Physalis group showing absence of collagen fibers. (d) Physalis $+\mathrm{CCl}_{4}$ group showing sporadic, small fibrotic lesions in the periportal zone and reduction in collagen fibers deposition. Original magnification 200x.

constituents. On comparison of the mass spectra of the constituents with Wiley9 combined with NIST 11 libraries, the 29 phytoconstituents were characterized and identified (Supplementary data, Table S1, in the Supplementary Material available online at http://dx.doi.org/10.1155/2014/381413). The major phytochemical constituent's mass spectra are kaempferol 3-O-rutinoside (1.40\%), Quercetin 3,4',7-trimethyl ether (3.11\%), Folic Acid (0.95\%), 1,25-Dihydroxyvitamin D2 (1.27\%), Lucenin-2 (1.50\%), Betulin (0.62\%), (5á)Pregnane3,20á-diol (0.97\%).

3.2. Histopathologic Findings. Control animals showed no abnormality (Figures 3(a) and 4(a)), whereas liver sections of $\mathrm{CCl}_{4}$-intoxicated rats showed excessive liver damage with necrosis and inflammation of hepatocytes (Figure 3(b)) and collagen accumulation (Figure 4(b)). Physalis-treated animals showed no abnormalities as well (Figures 3(c) and 4(c)), whereas combined treated groups marked decrease in the liver injury and collagen accumulation as compared with $\mathrm{CCl}_{4}$-treated animals (Figures 3(d) and 4(d)).
3.3. Biochemical Findings. $\mathrm{CCl}_{4}$ injections to the experimental animals caused hepatotoxicity which is indicated by the elevation of the activities of the sera AST, A LT, $\gamma$-GT, ALP, and TB level, while supplementation of physalis juice exhibited a significant decrease in the levels of these marker enzymes and restored it to the control values as shown in Table 2.

MDA, an end product of lipid peroxidation, is widely used as a marker of lipid peroxidation. $\mathrm{CCl}_{4}$ injection resulted in a significant increase in MDA in the intoxicated group while treatment withphysalis has significantly reduced the liver injury indicating the hepatoprotective effect of physalis juice (Table 3). The inflammatory marker NO was elevated in the $\mathrm{CCl}_{4}$-treated group compared to other groups; this result was further confirmed by the results of mRNA transcripts which have shown increase in the expression of iNOS, while in the treatment group (Group IV) they showed marked reduction in their expression (Figure 5)

Compromised hepatic function is always associated with a state of oxidative stress in liver tissues and serum. Thus, the activities of the redox system were measured in liver tissues. 
TABle 3: Sera MDA, NO, and GSH and hepatic MDA, NO, GSH, GRd, GST, and GPx in different studied groups.

\begin{tabular}{lcccc}
\hline Parameters & Group I & Group II & Group III & Group IV \\
\hline Serum MDA $(\mathrm{nmol} / \mathrm{mL})$ & $32.37 \pm 0.61$ & $50.21 \pm 1.46^{\mathrm{a}}$ & $23.18 \pm 1.51^{\mathrm{a}}$ & $37.52 \pm 1.38^{\mathrm{b}}$ \\
Serum NO $(\mu \mathrm{mol} / \mathrm{L})$ & $47.33 \pm 1.64$ & $101.13 \pm 4.79^{\mathrm{a}}$ & $52.30 \pm 2.99$ & $80.10 \pm 2.10^{\mathrm{ab}}$ \\
Serum GSH $(\mathrm{mmol} / \mathrm{mL})$ & $53.02 \pm 2.86$ & $39.13 \pm 1.31^{\mathrm{a}}$ & $72.00 \pm 4.91^{\mathrm{a}}$ & $63.46 \pm 3.65^{\mathrm{ab}}$ \\
Hepatic MDA $(\mathrm{nmol} / \mathrm{g}$ tissue) & $427.19 \pm 4.79$ & $591.45 \pm 12.47^{\mathrm{a}}$ & $360.75 \pm 7.85^{\mathrm{a}}$ & $406.82 \pm 2.80^{\mathrm{b}}$ \\
Hepatic NO $(\mu \mathrm{mol} / \mathrm{g}$ tissue) & $128.54 \pm 2.39$ & $226.50 \pm 2.93^{\mathrm{a}}$ & $139.33 \pm 6.82$ & $184.59 \pm 8.67^{\mathrm{ab}}$ \\
Liver GSH $(\mathrm{mmol} / \mathrm{g}$ tissue) & $36.69 \pm 2.01$ & $25.09 \pm 1.47^{\mathrm{a}}$ & $55.51 \pm 2.73^{\mathrm{a}}$ & $44.16 \pm 5.66^{\mathrm{b}}$ \\
Hepatic GRd $(\mu \mathrm{mol} / \mathrm{g}$ tissue) & $102.48 \pm 8.97$ & $41.5297 \pm 3.15^{\mathrm{a}}$ & $105.16 \pm 10.95$ & $86.4085 \pm 5.75^{\mathrm{b}}$ \\
Hepatic GST $(\mu \mathrm{mol} / \mathrm{h} / \mathrm{g}$ tissue) & $0.27 \pm 0.03$ & $0.12 \pm 0.01^{\mathrm{a}}$ & $0.31 \pm 0.02$ & $0.22 \pm 0.03^{\mathrm{ab}}$ \\
Hepatic GPx $(\mathrm{U} / \mathrm{g}$ tissue $)$ & $1722.43 \pm 69.21$ & $616.02 \pm 27.76^{\mathrm{a}}$ & $2054.37 \pm 54.68^{\mathrm{a}}$ & $1532.68 \pm 38.97^{\mathrm{b}}$ \\
\hline
\end{tabular}

Values are means $\pm \operatorname{SEM}(n=7)$.

${ }^{\mathrm{a}} P<0.05$, significant change with respect to Group I; ${ }^{b} P<0.05$, significant change with respect to Group II.

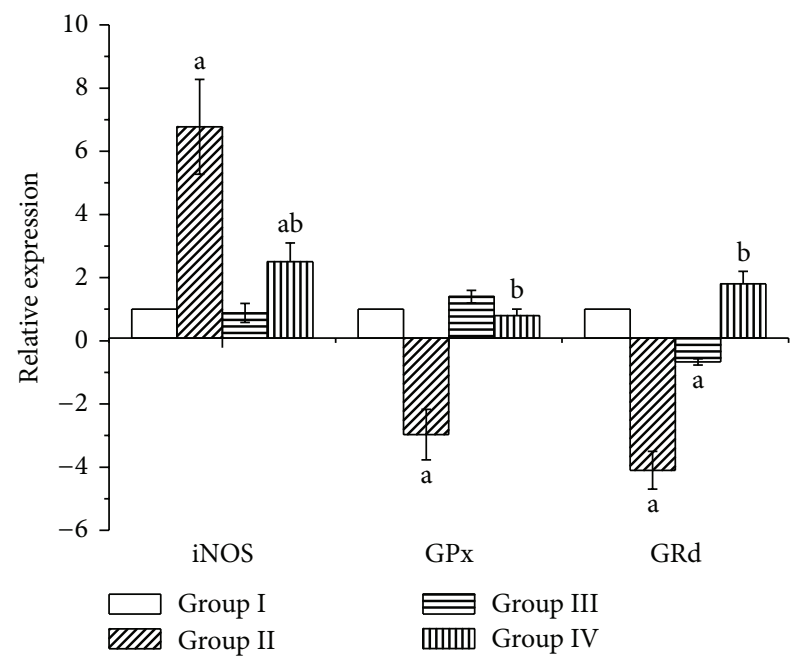

FIGURE 5: Relative quantification using RT-qPCR of mRNA expression of iNOS, GPx, and GRd genes in liver of rats treated with $\mathrm{CCl}_{4}$ and physalis juice. Values are means $\pm \operatorname{SEM}(n=7) .{ }^{\mathrm{a}} P<0.05$, significant change with respect to Group I; ${ }^{b} P<0.05$, significant change with respect to Group II.

Antioxidant enzymes such as SOD, CAT, GPx, GRd, and GST, as well as glutathione as nonenzymatic antioxidant substance, were estimated in the present study. There was a significant decrease in GSH content in the serum and liver homogenates of $\mathrm{CCl}_{4}$-treated groups as compared to the control at $P<$ 0.05. The supplementation of physalis with $\mathrm{CCl}_{4}$ caused a significant increase in $\mathrm{GSH}$ when compared with $\mathrm{CCl}_{4}$ group and returned its content to the control level (Table 3). GPx, GRd, and GST activities were also significantly decreased in the liver tissues of rats injected with $\mathrm{CCl}_{4}$ (Table 3). The decreases in GPx and GRd were confirmed by results of real time PCR which showed decreases in mRNA expressions by 2.9-fold for GPx and 4-fold for GRd but supplementation with physalis juice was able to significantly ameliorate these enzymes after 12 weeks of treatment concurrently with $\mathrm{CCl}_{4}$ (Figure 5).

Carbon tetrachloride decreased the activities of SOD and CAT, compared to the control group (Figure 6). Rats supplemented withphysalis juice together with $\mathrm{CCl}_{4}$

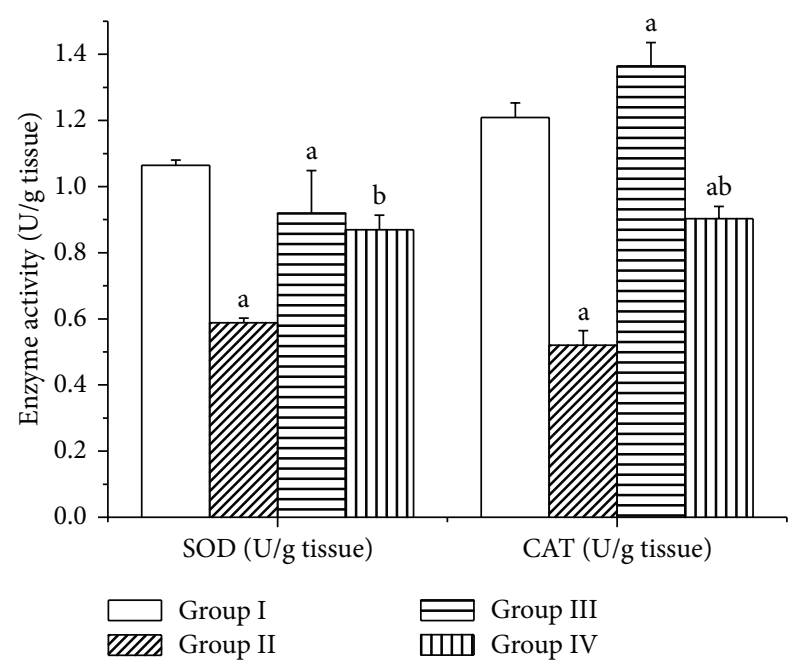

Figure 6: Effects of physalis juice on superoxide dismutase and catalase inhibition in different brain regions of rats treated with $\mathrm{CCl}_{4}$. Values are means $\pm \operatorname{SEM}(n=7) .{ }^{\mathrm{a}} P<0.05$, significant change with respect to Group I; ${ }^{b} P<0.05$, significant change with respect to Group II.

for 12 weeks experienced a significant increase in SOD and CAT activities compared to the $\mathrm{CCl}_{4}$-treated group. These improvements indicated thatphysalis juice has antioxidative and beneficial effects for liver recovery from $\mathrm{CCl}_{4}$ injury.

3.4. Immunohistochemistry Results. Immunohistochemistry revealed a high expression of MMP-9 in the $\mathrm{CCl}_{4}$-treated rats which were reduced in physalis $+\mathrm{CCl}_{4}$ group, indicating the antifibrotic effect of physalisjuice (Figure $7(\mathrm{~d})$ ).

\section{Discussion}

The oxidative stress induced by $\mathrm{CCl}_{4}$, an established model for the evaluation of hepatotoxicity [28-30], was manifested in the hepatic injury observed in the animals treated with $\mathrm{CCl}_{4}$. This is due to the CYP P450-mediated metabolism of $\mathrm{CCl}_{4}$ to reactive metabolites: $\mathrm{CCl}_{3}{ }^{\circ}$ and $\mathrm{CCl}_{3} \mathrm{OO}^{\circ}$. These radicals bind irreversibly to cellular molecules such 

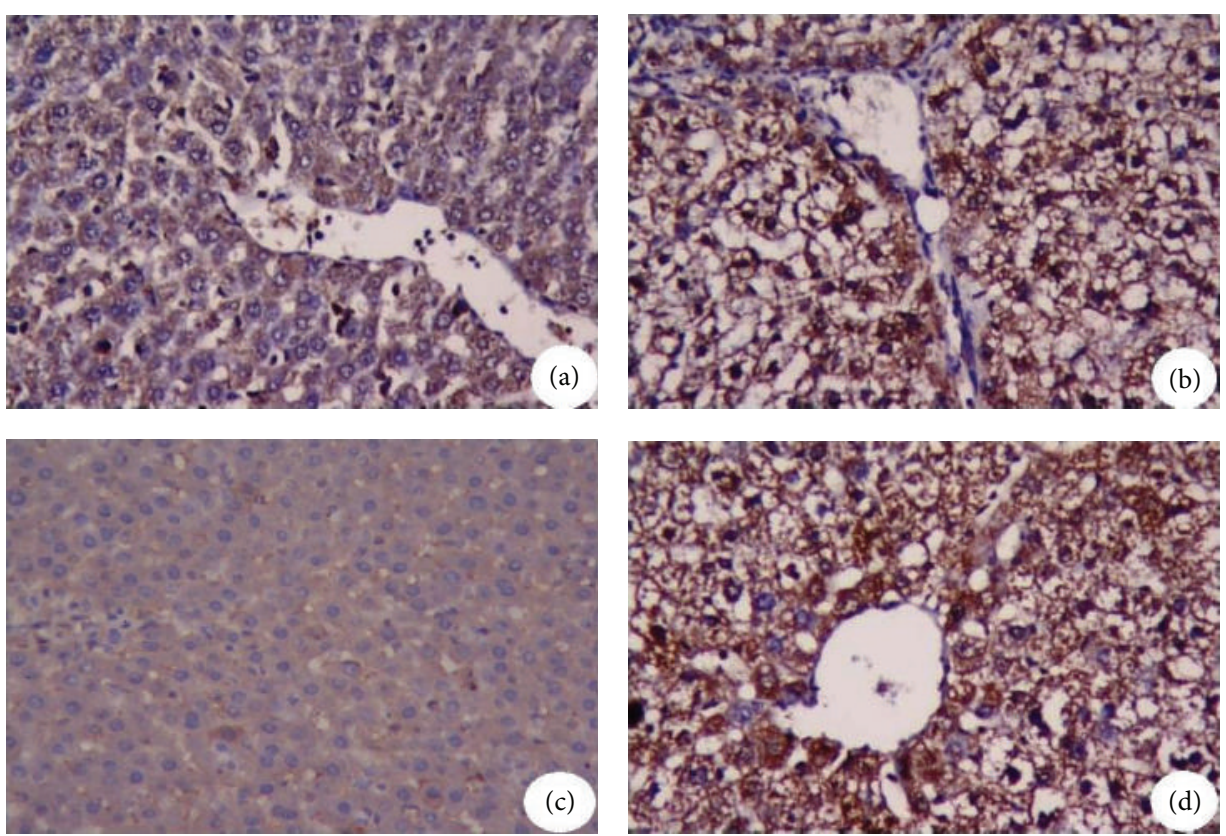

FIgURE 7: The expression and specific tissue distribution of MMP-9. (a) The liver sections from control rats showed low MMP-9 immunopositive reaction in the hepatic cells. (b) In the livers of rats receiving $\mathrm{CCl}_{4}$ for 12 weeks, high MMP-9 expression. (c) Rats receiving physalis juice for 12 weeks show weak immunopositive reaction for MMP-9 expression in hepatic cells. (d) The livers of rats receiving physalis juice concurrently with $\mathrm{CCl}_{4}$ showed staining pattern similar or more than to the control animals. Original magnification 400x.

as nucleic acid, protein, and lipids, especially the polyunsaturated fatty acids to initiate a process of autocatalytic lipid peroxidation by attacking the methylene bridges of unsaturated fatty acid side chains. This invariably affects the mitochondrial permeability, endoplasmic sequestration, and homeostasis and ultimately in cell damage [31]. Our data show that treatment with $\mathrm{CCl}_{4}$ at a dose of $2 \mathrm{~mL} / \mathrm{kg}$ body weight one time per week for 12 weeks led to the development of hepatic injury and fibrosis in rats. The results obtained in this work are similar to the findings of Ganie et al. [32] and Breikaa et al. [33] who have shown the hepatotoxic effect of $\mathrm{CCl}_{4}$

We further tried to evaluate physalis juice hepatoprotection and to show whether it attenuated oxidative stress and inhibited fibrosis in rats treated with $\mathrm{CCl}_{4}$. We found that, after supplementation of physalis juice, liver tissue showed a more or less normal lobular pattern with mild degree of necrosis and lymphocytic infiltration almost comparable to normal control.

The general chemical composition of Physalis peruviana L. fruit juice has many advantages for its use in medicine [34]. Plant extracts of physalis show antioxidant activity [35] as well as antihepatotoxic $[36,37]$, antiproliferative effects on hepatoma cells [38] and anti-inflammatory activity [39]. The hepatoprotective effect may be due to presence of quercetin which is one of the main phenolic components present inphysalis and a well-known hepatoprotective agent $[30,40$, 41].

A first indication of hepatic damage induced by $\mathrm{CCl}_{4}$ was obtained by the evaluation of ALT, AST, ALP, and $\gamma$ GT. These enzymes have been identified in cytotoxic and cholestatic hepatic injuries. The reversal of these alterations by physalis juice is a clear indication of the improvement of the functional status of hepatocytes with preservation of cellular architecture [42] indicating the hepatoprotective activity of physalis.

MDA was one of the main lipid peroxidation products, its elevated levels could reflect the degrees of lipid peroxidation injury in hepatocytes [43], and administration ofphysalis juice markedly decreases MDA levels indicating its antiperoxidative effect.

NO plays crucial roles in inflammation and liver injury [44]. It is produced in large quantities by Kupffer cells, endothelial cells, and the hepatocytes themselves in response to tissue damage and inflammation induced by various xenobiotics including $\mathrm{CCl}_{4}$. In addition, its role in oxidative stress cannot be neglected, since high levels of NO have been associated with oxidative injury via lipid peroxide. Our results showed elevated levels of $\mathrm{NO}$ in the $\mathrm{CCl}_{4}$ intoxicated rats which is consistent with Breikaa et al. [33]. Our results were supported by the increase in iNOS mRNA gene expression. iNOS is responsible for initiation and propagation of the inflammatory cascade [45]; this elevation was significantly decreased after administration of physalis. This may be a potential mechanism by which physalis juice can act as antiinflammatory and thus protect the liver $[39,46]$.

Oxidative stress produced by free radicals is the main and primary step in $\mathrm{CCl}_{4}$ toxicity contributing to both onset and progression of fibrosis [31]. This was evidenced by enhanced lipid peroxidation, associated with decreased levels of GSH and the antioxidant enzymes system, namely, SOD, CAT, GPx, GRd, and GST. 
Many studies reported that these enzymes constitute a mutually supportive team of defense against ROS $[47,48]$. An interesting finding in our study is that treatment withphysalis juice attenuated the intoxications of $\mathrm{CCl}_{4}$ and significantly improved the activity of these enzymes; this indicates the antioxidant and antihepatotoxic effects of physalis which is similar to results obtained by Arun and Asha [36].

MMP-9 is considered a hallmark of fibrosis whose expression increases by tumor necrosis factor alpha and transforming growth factor beta during the onset of liver fibrogenesis [49]. Immunohistochemical detection in the present study revealed high expression of MMP-9 in the intoxicated rats compared to control group. It has been shown that general inhibitors of MMPs attenuate hepatic fibrosis or are useful to inhibit acute and chronic inflammatory or vascular diseases [50].

Another interesting finding of our study is that treatment withphysalis juice has downregulated the expression of MMP-9 and thus inhibiting fibrosis. The antioxidant and antifibrotic effect of physalis may be due to presence of quercetin [41]. Our GC-MS results have shown that it contains high amount of it. Quercetin belongs to an extensive class of polyphenolic flavonoid compounds almost ubiquitous in plants and plant food sources. Quercetin is considered to be a strong antioxidant due to its ability to scavenge free radicals and bind transition metal ions. These properties of quercetin allow it to inhibit lipid peroxidation [51] and have anti-inflammatory properties [52]. In addition to quercetin, physalis juice also contains kaempferol 3-Orutinoside. Kaempferol is known to be potential antioxidant due to its ability to scavenge free radicals and active oxygen species such as singlet oxygen, superoxide anion radical, and hydroxyl radicals [53]. The presence of these compounds could explain the antioxidant activity found in the crude extract.

\section{Conclusion}

The findings of the present study indicate the hepatoprotective effect of physalis on $\mathrm{CCl}_{4}$ intoxicated rats. This was accompanied with improvements in liver function, decreasing collagen areas and hepatic fibrosis. The underlying mechanisms for this hepatoprotection may be due scavenging free radicals, as well as decreasing the expression of the wellknown fibrotic marker MMP-9. Thus blocking the oxidative stress pathway may be of therapeutic value in treatment of liver injury and fibrosis.

\section{Conflict of Interests}

The authors declare that there is no conflict of interests regarding the publication of this paper.

\section{Acknowledgment}

The authors extend their appreciation to the deanship of scientific research at king Saud University for funding the work through the research group Project no. RGPVPP-074.

\section{References}

[1] F. Tacke, T. Luedde, and C. Trautwein, "Inflammatory pathways in liver homeostasis and liver injury," Clinical Reviews in Allergy and Immunology, vol. 36, no. 1, pp. 4-12, 2009.

[2] P. Vitaglione, F. Morisco, N. Caporaso, and V. Fogliano, "Dietary antioxidant compounds and liver health," Critical Reviews in Food Science and Nutrition, vol. 44, no. 7-8, pp. 575-586, 2004.

[3] Y.-W. Hsu, C.-F. Tsai, W.-H. Chang, Y.-C. Ho, W.-K. Chen, and F.-J. Lu, "Protective effects of Dunaliella salina-a carotenoidsrich alga, against carbon tetrachloride-induced hepatotoxicity in mice," Food and Chemical Toxicology, vol. 46, no. 10, pp. 33113317, 2008.

[4] L. R. Pohl, R. D. Schulick, R. J. Highet, and J. W. George, "Reductive-oxygenation mechanism of metabolism of carbon tetrachloride to phosgene by cytochrome P-450," Molecular Pharmacology, vol. 25, no. 2, pp. 318-321, 1984.

[5] M. Kurata, M. Suzuki, and N. S. Agar, "Antioxidant systems and erythrocyte life-span in mammals," Comparative Biochemistry and Physiology B: Biochemistry and Molecular Biology, vol. 106, no. 3, pp. 477-487, 1993.

[6] S. Ghatak, A. Biswas, G. K. Dhali, A. Chowdhury, J. L. Boyer, and A. Santra, "Oxidative stress and hepatic stellate cell activation are key events in arsenic induced liver fibrosis in mice," Toxicology and Applied Pharmacology, vol. 251, no. 1, pp. 59-69, 2011.

[7] Y. Fu, S. Zheng, J. Lin, J. Ryerse, and A. Chen, "Curcumin protects the rat liver from CCl4-caused injury and fibrogenesis by attenuating oxidative stress and suppressing inflammation," Molecular Pharmacology, vol. 73, no. 2, pp. 399-409, 2008.

[8] G. Deng, J. Wang, Q. Zhang et al., "Hepatoprotective effects of phloridzin on hepatic fibrosis induced by carbon tetrachloride against oxidative stress-triggered damage and fibrosis in rats," Biological \& Pharmaceutical Bulletin, vol. 35, no. 7, pp. 1118-1125, 2012.

[9] M. S. Othman, A. Nada, H. S. Zaki, and A. E. Abdel Moneim, "Effect of Physalis peruviana L. on cadmium-induced testicular toxicity in rats," Biological Trace Element Research, 2014.

[10] M. S. Othman, G. Safwat, M. Aboulkhair, and A. E. Abdel Moneim, "The Potential Effect of Berberine in Mercury-induced Hepatorenal Toxicity in Albino Rats," Food and Chemical Toxicology, 2014.

[11] S.-T. Fang, J.-K. Liu, and B. Li, "Ten new withanolides from Physalis peruviana," Steroids, vol. 77, no. 1-2, pp. 36-44, 2012.

[12] I.-K. Wang, S.-Y. Lin-Shiau, and J.-K. Lin, "Induction of apoptosis by apigenin and related flavonoids through cytochrome $\mathrm{c}$ release and activation of caspase- 9 and caspase- 3 in leukaemia HL-60 cells," European Journal of Cancer, vol. 35, no. 10, pp. 1517-1525, 1999.

[13] M. Nishikimi, N. Appaji Rao, and K. Yagi, "The occurrence of superoxide anion in the reaction of reduced phenazine methosulfate and molecular oxygen," Biochemical and Biophysical Research Communications, vol. 46, no. 2, pp. 849-854, 1972.

[14] A. E. Abdel Moneim, "The neuroprotective effects of purslane (Portulaca oleracea) on rotenone-induced biochemical changes and apoptosis in brain of rat," CNS Neurological Disorders Drug Targets, vol. 12, no. 6, pp. 830-841, 2013.

[15] D. H. Sohn, Y.-P. Yun, K. S. Park, R. L. Veech, and B. J. Song, "Post-translational reduction of cytochrome P450IIE by CCl4, its substrate," Biochemical and Biophysical Research Communications, vol. 179, no. 1, pp. 449-454, 1991. 
[16] S. Reitman and S. Frankel, "A colorimetric method for the determination of serum glutamic oxalacetic and glutamic pyruvic transaminases," American journal of clinical pathology, vol. 28, no. 1, pp. 56-63, 1957.

[17] G. Szasz, "A kinetic photometric method for serum gammaglutamyl transpeptidase," Clinical Chemistry, vol. 15, no. 2, pp. 124-136, 1969.

[18] A. Belfield and D. M. Goldberg, "Revised assay for serum phenyl phosphatase activity using 4-amino-antipyrine," Enzyme, vol. 12, no. 5, pp. 561-573, 1971.

[19] C. C. Garber, "Jendrassik-Grof analysis for total and direct bilirubin in serum with a centrifugal analyzer," Clinical Chemistry, vol. 27, pp. 1410-1416, 1981.

[20] H. Ohkawa, N. Ohishi, and K. Yagi, "Assay for lipid peroxides in animal tissues by thiobarbituric acid reaction," Analytical Biochemistry, vol. 95, no. 2, pp. 351-358, 1979.

[21] L. C. Green, D. A. Wagner, and J. Glogowski, "Analysis of nitrate, nitrite, and $[15 \mathrm{~N}]$ nitrate in biological fluids," Analytical Biochemistry, vol. 126, no. 1, pp. 131-138, 1982.

[22] G. L. Ellman, "Tissue sulfhydryl groups", Archives of Biochemistry and Biophysics, vol. 82, no. 1, pp. 70-77, 1959.

[23] H. Aebi, "Catalase in vitro," Methods in Enzymology, vol. 105, pp. 121-126, 1984.

[24] D. E. Paglia and W. N. Valentine, "Studies on the quantitative and qualitative characterization of erythrocyte glutathione peroxidase," The Journal of Laboratory and Clinical Medicine, vol. 70, no. 1, pp. 158-169, 1967.

[25] W. H. Habig, M. J. Pabst, and W. B. Jakoby, "Glutathione S-transferases. The first enzymatic step in mercapturic acid formation," The Journal of Biological Chemistry, vol. 249, no. 22, pp. $7130-7139,1974$.

[26] V. M. Factor, A. Kiss, J. T. Woitach, P. J. Wirth, and S. S. Thorgeirsson, "Disruption of redox homeostasis in the transforming growth factor- $\alpha / \mathrm{c}-$ myc transgenic mouse model of accelerated hepatocarcinogenesis," The Journal of Biological Chemistry, vol. 273, no. 25, pp. 15846-15853, 1998.

[27] A. E. Abdel Moneim and K. M. El-Deib, "The Possible protective effects of Physalis peruviana on carbon tetrachloride-induced nephrotoxicity in male albino rats," Life Science Journal, vol. 9, no. 3, pp. 1038-1052, 2012.

[28] J.-W. Yun, C.-W. Kim, I.-H. Bae et al., "Determination of the key innate genes related to individual variation in carbon tetrachloride-induced hepatotoxicity using a pre-biopsy procedure," Toxicology and Applied Pharmacology, vol. 239, no. 1, pp. 55-63, 2009.

[29] O. A. Adesanoye and E. O. Farombi, "Hepatoprotective effects of Vernonia amygdalina (astereaceae) in rats treated with carbon tetrachloride," Experimental and Toxicologic Pathology, vol. 62, no. 2, pp. 197-206, 2010.

[30] E. Coballase-Urrutia, J. Pedraza-Chaverri, N. CárdenasRodríguez et al., "Hepatoprotective effect of acetonic and methanolic extracts of Heterotheca inuloides against CCl4induced toxicity in rats," Experimental and Toxicologic Pathology, vol. 63, no. 4, pp. 363-370, 2011.

[31] M. Boll, L. W. D. Weber, E. Becker, and A. Stampfl, "Mechanism of carbon tetrachloride-induced hepatotoxicity. Hepatocellular damage by reactive carbon tetrachloride metabolites," Zeitschrift fur Naturforschung C: Journal of Biosciences, vol. 56, no. 7-8, pp. 649-659, 2001.

[32] S. A. Ganie, B. A. Zargar, A. Masood, and M. A. Zargar, "Hepatoprotective and antioxidant activity of rhizome of
Podophyllum hexandrum against carbon tetra chloride induced hepatotoxicity in rats," Biomedical and Environmental Sciences, vol. 26, no. 3, pp. 209-221, 2013.

[33] R. M. Breikaa, M. M. Algandaby, E. El-Demerdash, and A. B. Abdel-Naim, "Multimechanistic antifibrotic effect of biochanin a in rats: implications of proinflammatory and profibrogenic mediators," PLoS ONE, vol. 8, no. 7, Article ID e69276, 2013.

[34] M. F. Ramadan, "Bioactive phytochemicals, nutritional value, and functional properties of cape gooseberry (Physalis peruviana): an overview," Food Research International, vol. 44, no. 7, pp. 1830-1836, 2011.

[35] J. C. Chang, C. C. Lin, S. J. Wu et al., "Antioxidative and hepatoprotective effects of Physalis peruviana extract against acetaminophen-induced liver injury in rats," Pharmaceutical Biology, vol. 46, no. 10-11, pp. 724-731, 2008.

[36] M. Arun and V. V. Asha, "Preliminary studies on antihepatotoxic effect of Physalis peruviana Linn. (Solanaceae) against carbon tetrachloride induced acute liver injury in rats," Journal of Ethnopharmacology, vol. 111, no. 1, pp. 110-114, 2007.

[37] S. E. El-Gengaihi, E. E. Hassan, M. A. Hamed, H. G. Zahran, and M. A. Mohammed, "Chemical composition and biological evaluation of Physalis peruviana root as hepato-renal protective agent," Journal of Dietary Supplements, vol. 10, no. 1, pp. 39-53, 2013.

[38] S.-J. Wu, L.-T. Ng, D.-L. Lin, S.-N. Huang, S.-S. Wang, and C.-C. Lin, "Physalis peruviana extract induces apoptosis in human Hep G2 cells through CD95/CD95L system and the mitochondrial signaling transduction pathway," Cancer Letters, vol. 215, no. 2, pp. 199-208, 2004.

[39] S. J. Wu, J. Y. Tsai, S. P. Chang et al., "Supercritical carbon dioxide extract exhibits enhanced antioxidant and anti-inflammatory activities of Physalis peruviana," Journal of Ethnopharmacology, vol. 108, no. 3, pp. 407-413, 2006.

[40] A. K. Mandal and N. Das, "Sugar coated liposomal flavonoid: a unique formulation in combating carbontetrachloride induced hepatic oxidative damage," Journal of Drug Targeting, vol. 13, no. 5, pp. 305-315, 2005.

[41] K. H. Janbaz, S. A. Saeed, and A. H. Gilani, "Studies on the protective effects of caffeic acid and quercetin on chemicalinduced hepatotoxicity in rodents," Phytomedicine, vol. 11, no. 5, pp. 424-430, 2004.

[42] A. U. Tatiya, S. J. Surana, M. P. Sutar, and N. H. Gamit, "Hepatoprotective effect of poly herbal formulation against various hepatotoxic agents in rats," Pharmacognosy Research, vol. 4, no. 1, pp. 50-56, 2012.

[43] J. Kim, J. Chehade, J. L. Pinnas, and A. D. Mooradian, "Effect of select antioxidants on malondialdehyde modification of proteins," Nutrition, vol. 16, no. 11-12, pp. 1079-1081, 2000.

[44] T.-M. Leung, M.-L. Fung, E. C. Liong, T. Y. H. Lau, A. A. Nanji, and G. L. Tipoe, "Role of nitric oxide in the regulation of fibrogenic factors in experimental liver fibrosis in mice," Histology and Histopathology, vol. 26, no. 2, pp. 201-211, 2011.

[45] W. Zhu and P. C. W. Fung, "The roles played by crucial free radicals like lipid free radicals, nitric oxide, and enzymes NOS and NADPH in CCl4-induced acute liver injury of mice," Free Radical Biology and Medicine, vol. 29, no. 9, pp. 870-880, 2000.

[46] S. E. El-Gengaihi, M. A. Hamed, R. Khalaf-Allah, and M. A. Mohammed, "Golden berry juice attenuates the severity of hepatorenal injury," Journal of Dietary Supplements, vol. 10, no. 4, pp. 357-369, 2013.

[47] B. Halliwell and J. M. C. Gutteridge, "Cellular responses to oxidative stress: adaptation, damage, repair, senescence and 
death," in Free Radicals in Biology and Medicine, pp. 187-267, Oxford University Press, Oxford, UK, 2007.

[48] M. Valko, D. Leibfritz, J. Moncol, M. T. D. Cronin, M. Mazur, and J. Telser, "Free radicals and antioxidants in normal physiological functions and human disease," International Journal of Biochemistry and Cell Biology, vol. 39, no. 1, pp. 44-84, 2007.

[49] E. Vassiliadis, D. V. Larsen, R. E. Clausen et al., "Measurement of co3-610, a potential liver biomarker derived from matrix metalloproteinase-9 degradation of collagen type iii, in a rat model of reversible carbon-tetrachloride-induced fibrosis," Biomarker Insights, vol. 6, pp. 49-58, 2011.

[50] A. Kahraman, S. F. Bronk, S. Cazanave et al., "Matrix metalloproteinase inhibitor, CTS-1027, attenuates liver injury and fibrosis in the bile duct-ligated mouse," Hepatology Research, vol. 39, no. 8, pp. 805-813, 2009.

[51] P. C. H. Hollman, J. M. P. Van Trijp, M. J. B. Mengelers, J. H. M. De Vries, and M. B. Katan, "Bioavailability of the dietary antioxidant flavonol quercetin in man," Cancer Letters, vol. 114, no. 1-2, pp. 139-140, 1997.

[52] A. W. Boots, L. C. Wilms, E. L. R. Swennen, J. C. S. Kleinjans, A. Bast, and G. R. M. M. Haenen, "In vitro and ex vivo anti-inflammatory activity of quercetin in healthy volunteers," Nutrition, vol. 24, no. 7-8, pp. 703-710, 2008.

[53] S. J. N. Tatsimo, J. D. D. D. Tamokou, L. Havyarimana et al., "Antimicrobial and antioxidant activity of kaempferol rhamnoside derivatives from Bryophyllum pinnatum," BMC Research Notes, vol. 5, p. 158, 2012. 


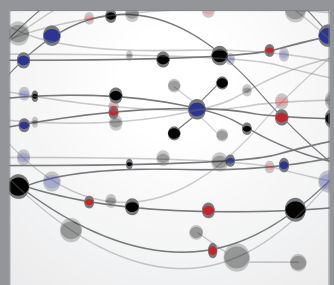

The Scientific World Journal
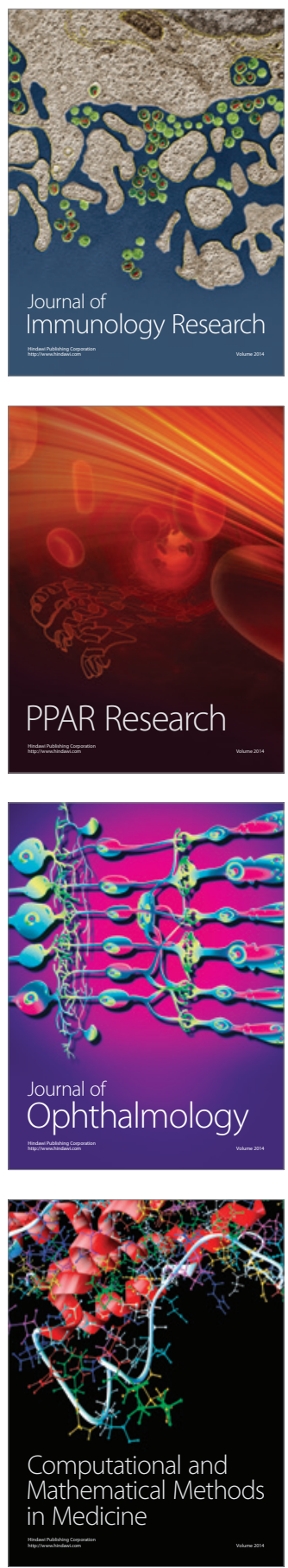

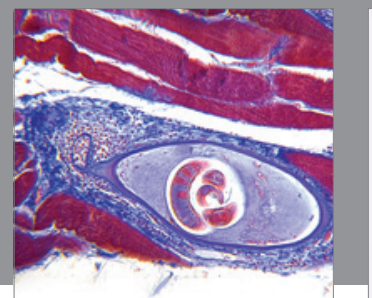

Gastroenterology

Research and Practice
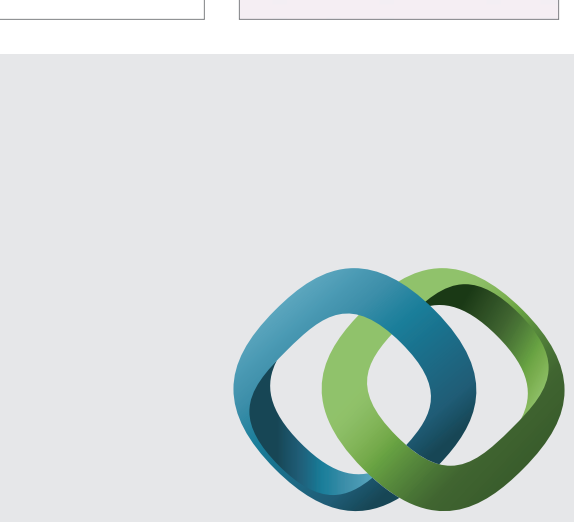

\section{Hindawi}

Submit your manuscripts at

http://www.hindawi.com
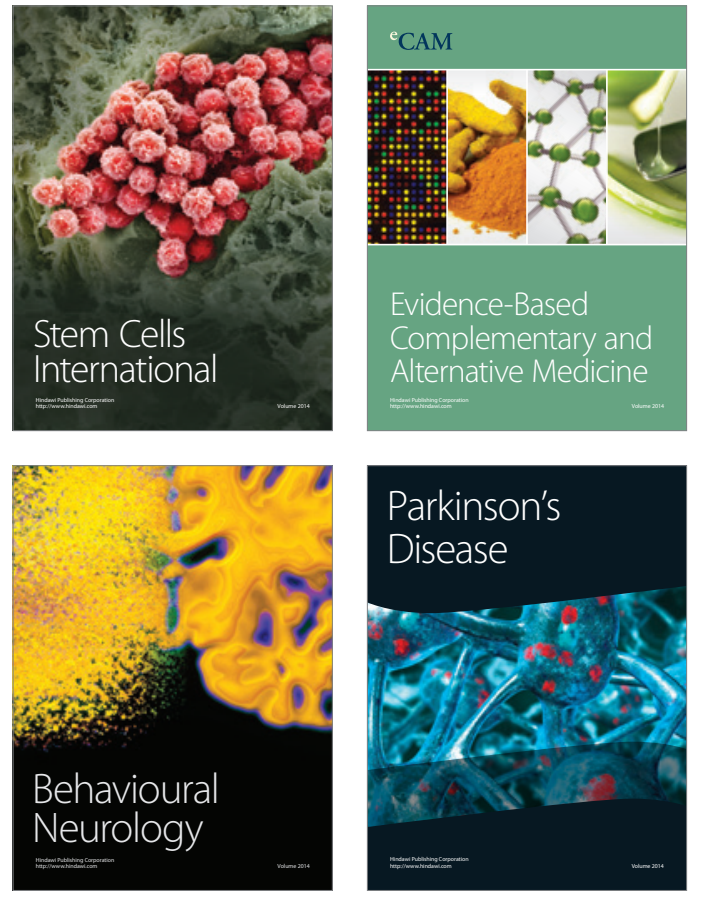
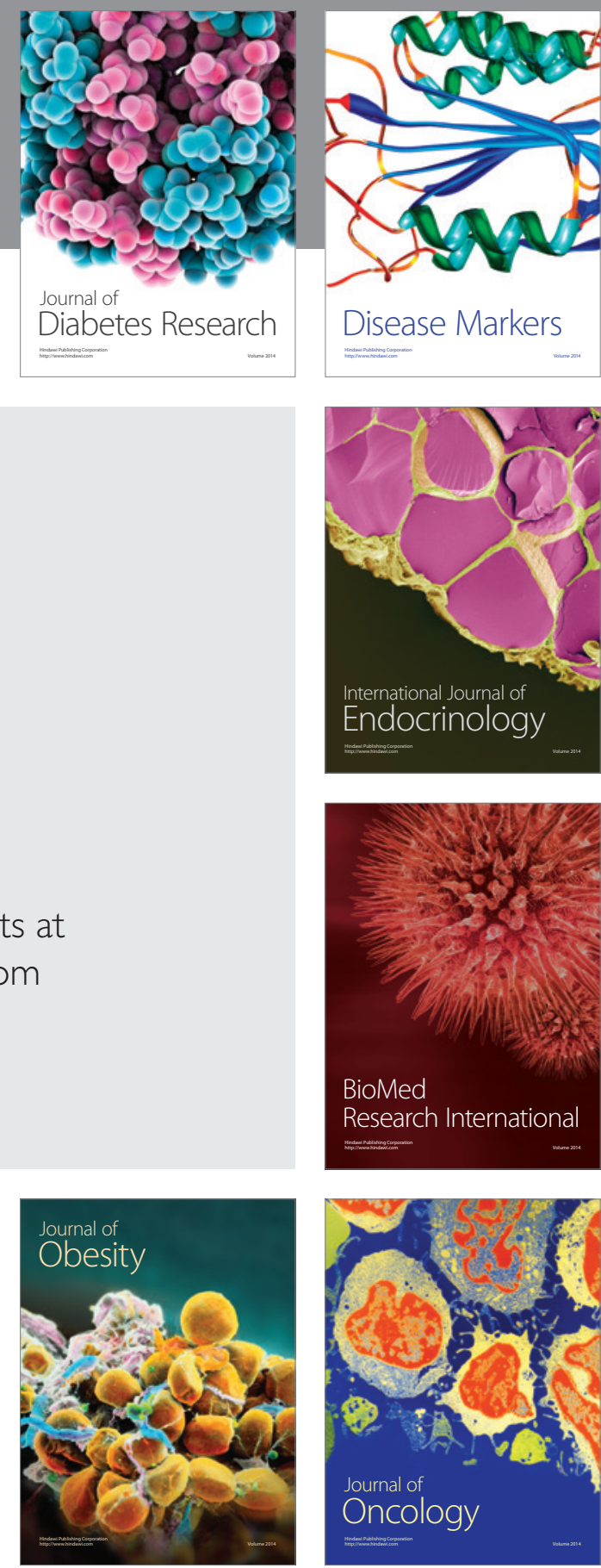

Disease Markers
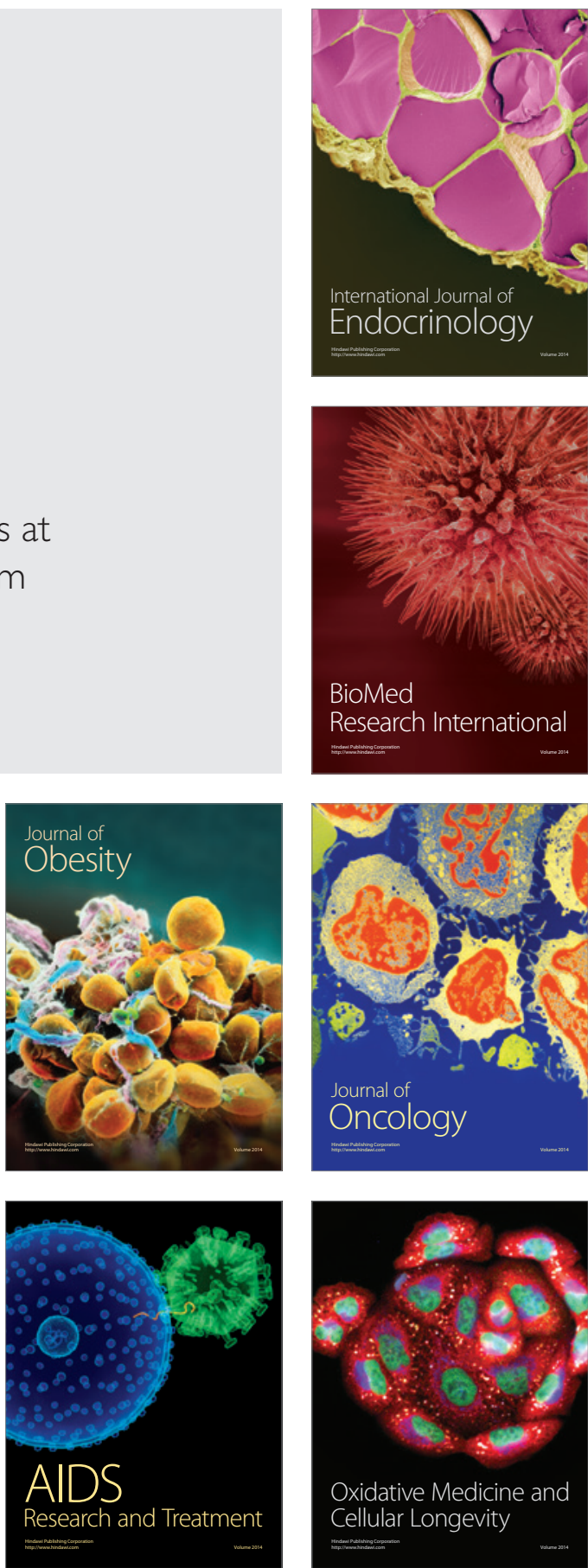